April 2006

\title{
Pro-opiomelanocortin co-localizes with corticotropin-releasing factor in axon terminals of the noradrenergic nucleus locus coeruleus
}

\author{
Beverly A.S. Reyes \\ Thomas Jefferson University \\ Julia D. Glaser \\ Thomas Jefferson University \\ Ronaldo Magtoto \\ Thomas Jefferson University \\ Elisabeth K. van Bockstaele

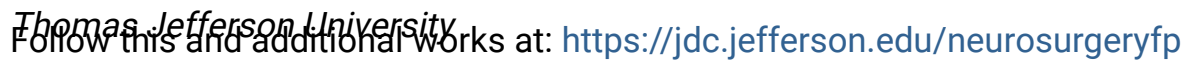 \\ Part of the Medical Neurobiology Commons \\ Let us know how access to this document benefits you
}

\section{Recommended Citation}

Reyes, Beverly A.S.; Glaser, Julia D.; Magtoto, Ronaldo; and van Bockstaele, Elisabeth K., "Proopiomelanocortin co-localizes with corticotropin-releasing factor in axon terminals of the noradrenergic nucleus locus coeruleus" (2006). Department of Neurosurgery Faculty Papers.

Paper 3.

https://jdc.jefferson.edu/neurosurgeryfp/3

This Article is brought to you for free and open access by the Jefferson Digital Commons. The Jefferson Digital Commons is a service of Thomas Jefferson University's Center for Teaching and Learning (CTL). The Commons is a showcase for Jefferson books and journals, peer-reviewed scholarly publications, unique historical collections from the University archives, and teaching tools. The Jefferson Digital Commons allows researchers and interested readers anywhere in the world to learn about and keep up to date with Jefferson scholarship. This article has been accepted for inclusion in Department of Neurosurgery Faculty Papers by an authorized administrator of the Jefferson Digital Commons. For more information, please contact: JeffersonDigitalCommons@jefferson.edu. 


\title{
Proopiomelanocortin co-localizes with corticotropin-releasing factor in axon terminals of the noradrenergic nucleus locus coeruleus
}

Beverly A. S. Reyes, Julia D. Glaser, Ronaldo Magtoto and Elisabeth J. Van Bockstaele

\author{
Department of Neurosurgery \\ Thomas Jefferson University \\ Farber Institute for Neurosciences \\ Philadelphia, PA 19107
}

Corresponding Author: $\quad$ Beverly A. S. Reyes, Ph.D.

Department of Neurosurgery

Farber Institute for Neurosciences

Thomas Jefferson University

900 Walnut Street, Suite 400

Philadelphia, PA 19107

Voice: (215) 503-1245

FAX: (215) 955-4949

e-mail: bsr103@jefferson.edu

Running Title: POMC and CRF co-localization in the LC

Total number of pages: 27

Total number of figures: 5

Total number of words in

(i) the whole manuscript : $\quad 6,539$

(ii) the abstract : 243

(iii) the introduction : 575

Keywords: $\quad \beta$-endorphin; electron microscopy; immunofluorescence; tyrosine hydroxylase 


\begin{abstract}
We previously demonstrated that the opioid peptide, enkephalin, and corticotropinreleasing factor $(\mathrm{CRF})$ are occasionally co-localized in individual axon terminals but more frequently converge on common dendrites in the locus coeruleus (LC). To further examine potential opioid co-transmitters in CRF afferents, we investigated the distribution of proopiomelanocortin (POMC), the precursor that yields the potent bioactive peptide, $\beta$-endorphin, with respect to CRF immunoreactivity using immunofluorescence and immunoelectron microscopic analyses of the LC. Coronal sections were collected through the dorsal pontine tegmentum of rat brain and processed for immunocytochemical detection of POMC and CRF or tyrosine hydroxylase (TH). POMC-immunoreactive processes exhibited a distinct distribution within the LC as compared to the enkephalin family of opioid peptides. Specifically, POMC fibers were enriched in the ventromedial aspect of the LC with fewer fibers present dorsolaterally. Immunofluorescence microscopy showed frequent co-existence of POMC and CRF in varicose processes that overlapped $\mathrm{TH}$-containing somatodendritic processes in the LC. Ultrastructural analysis showed POMC immunoreactivity in unmyelinated axons and axon terminals. Axon terminals containing POMC were filled with numerous large dense core vesicles. In sections processed for POMC and TH, approximately $29 \%$ of POMCcontaining axon terminals $(n=405)$ targeted dendrites that exhibited immunogold-silver labeling for $\mathrm{TH}$. Whereas, sections processed for POMC and CRF showed that $27 \%$ of POMC-labeled axon terminals $(n=657)$ also exhibited CRF immunoreactivity. Taken together, these data indicate that a subset of CRF afferents targeting the LC contain POMC and may be positioned to dually impact LC activity.
\end{abstract}




\section{Introduction}

We have previously demonstrated that corticotropin-releasing factor (CRF) and endogenous opioids interact in the locus coeruleus (LC) to modulate noradrenergic function (Valentino et al., 1992; Van Bockstaele et al., 1996a; Van Bockstaele et al., 1996b; Xu et al., 2004). Specifically, we showed that chronic morphine administration sensitized the LC neurons to CRF (Xu et al., 2004). In an effort to further elucidate interactions between CRF and opioid associated with peptides that modulate mu-opioid receptors, we examined here the distribution of proopiomelanocortin (POMC), an opioid precursor, and CRF in this noradrenergic nucleus.

POMC is processed to yield the potent bioactive peptide, $\beta$-endorphin, which is associated with stress regulation (Baubet et al., 1994). $\beta$-endorphin interacts with $\mu$ opioid receptors to mediate stress-induced analgesia (Rubinstein et al., 1996) and it has been implicated in nociception (Foley et al., 1979; Yaksh et al., 1982; Bertolini et al., 1986; Baubet et al., 1994). In the present study, the ultrastructural distribution of POMC and catecholamine-containing neurons in the LC that may likely underlie the effects of POMC were investigated using immunofluorescence and electron microscopy in the rat brain.

Previous studies suggest that the LC is densely innervated by processes exhibiting endogenous opioid peptides including leucine- and methionine-enkephalin (Drolet et al., 1992; Van Bockstaele et al., 1995; Van Bockstaele et al., 1996c; Van Bockstaele \& Chan, 1997; Van Bockstaele et al., 2000), $\beta$-endorphin (Bloom et al., 1978a; Bloom et al., 1978b), and dynorphin (Fallon \& Leslie, 1986). Likewise, LC neurons demonstrate a high concentration of opioid receptors including $\mu$-opioid receptors (Tempel \& Zukin, 
1987; Mansour et al., 1994; Mansour et al., 1995; Van Bockstaele et al., 1996a; Van Bockstaele et al., 1996b).

Known for its population of noradrenergic neurons, the LC projects throughout all levels of the neuroaxis (Foote et al., 1983). Thus, LC neurons serve as the prime source of NE in the forebrain (Aston-Jones et al., 1985; McCormick et al., 1991).

Electrophysiological and pharmacological studies showed a critical role of noradrenergic projections from the $\mathrm{LC}$ in the control of vigilance, attention and adaptive behavioral responses (Aston-Jones \& Bloom, 1981b; a; Aston-Jones et al., 1984; Aston-Jones et al., 1994). In fact, LC neurons exhibit the highest firing rates during waking and decreased activity during slow-wave sleep, and are nearly quiescent during paradoxical sleep (Aston-Jones \& Bloom, 1981a). Moreover, LC neurons respond to autonomic influences (Svensson, 1987) and are implicated in multiple autonomic functions (Morilak et al., 1987a; b; Miyawaki et al., 1991). Afferents that innervate LC neurons can remarkably influence the neural circuitry involved in the diversity of functions ascribed to the LC (Aston-Jones et al., 1991).

Corticotropin-releasing factor $(\mathrm{CRF})$, the hypothalamic neurohormone that initiates the adrenocorticotropin release through its actions on corticotrophs of the adenohypophysis (Vale et al., 1981; Cummings et al., 1983; Swanson et al., 1983), also acts as a neurotransmitter in extrahypophyseal circuits that mediate behavioral and autonomic responses to stressors. Anatomical studies have described CRFimmunoreactive fibers in noradrenergic LC neurons (Cummings et al., 1983; Swanson et al., 1983). Specifically, CRF-axon terminals target noradrenergic dendrites in the LC (Van Bockstaele et al., 1996d; Van Bockstaele et al., 1998b). In support of these data, 
physiological studies have shown that $\mathrm{CRF}$ administration intracerebroventricularly or by microinfusion into the LC activated LC neurons (Valentino et al., 1983; Curtis et al., 1997). In addition, CRF central administration or microinfusion into the LC increases NE levels in prefrontal cortex, a region which derives NE solely from the LC (Lavicky \& Dunn, 1993; Smagin et al., 1995).

Anatomically, medullary afferents to the LC originate from the nucleus of the solitary tract (NTS; (Van Bockstaele et al., 1998a; Van Bockstaele et al., 1999) that provides monosynaptic input to noradrenergic dendrites in the LC (Van Bockstaele et al., 1999) . Additionally, immunohistochemical and biochemical analyses have shown POMC (Schwartzberg \& Nakane, 1982) and CRF (Herbert \& Saper, 1990) containing cell bodies within the NTS. Taken together with the important role of these neuropeptides in stress regulation (Baubet et al., 1994; Rubinstein et al., 1996; Vale et al., 1981; Cummings et al., 1983; Swanson et al., 1983), it is important to elucidate the role of POMC afferents that may express CRF as a co-transmitter in the regulation of noradrenergic function.

\section{Materials and Methods}

\section{Tissue preparation}

Ten adult male Sprague-Dawley rats (Harlan Laboratories, Indianapolis, IN, USA) weighing 225-250 g were used for this study. Five rats were used for examining the cellular associations of POMC with tyrosine hydroxylase- (TH) or CRF-containing cellular profiles in the dorsal pontine tegmentum using immunofluorescence while five rats were used for examining cellular associations using electron microscopy. The rats were housed 2-3 per cage on a 12-h light schedule in a temperature controlled $\left(20^{\circ} \mathrm{C}\right)$ 
colony room. They were given standard rat chow and water. The procedures were approved by the Institutional Animal Care and Use Committee of Thomas Jefferson University and conformed to NIH guidelines. All efforts were made to utilize only the minimum number of animals necessary to produce reliable scientific data and attempts were made to minimize animal suffering.

\section{Immunofluorescence microscopy}

Rats were deeply anesthetized with sodium pentobarbital $(60 \mathrm{mg} / \mathrm{kg})$ and transcardially perfused through the ascending aorta with $500 \mathrm{ml}$ of $4 \%$ formaldehyde in 0.1 M phosphate buffer (PB; $\mathrm{pH} 7.4$ ). Brains were then removed and post fixed in $4 \%$ formaldehyde overnight at $4^{\circ} \mathrm{C}$. Forty micrometer thick sections through the LC were cut with a Vibratome (Technical Product International, St Louis, MO, USA) and rinsed extensively in 0.1 M PB and 0.1 M tris-buffered saline (TBS; $\mathrm{pH}$ 7.6). Sections were placed for $30 \mathrm{~min}$ in $1 \%$ sodium borohydride in $0.1 \mathrm{M}$ PB to remove reactive aldehydes and incubated in $0.5 \%$ bovine serum albumin (BSA) in $0.1 \mathrm{M}$ TBS for $30 \mathrm{~min}$. Subsequently, sections were then incubated in $0.5 \%$ bovine serum albumin (BSA) and $0.25 \%$ Triton $\mathrm{X}-100$ in $0.1 \mathrm{M}$ TBS for $30 \mathrm{~min}$ and rinsed extensively in $0.1 \mathrm{M}$ TBS. Subsequently, sections were processed for POMC and TH or POMC and CRF immunoreactivities.

Sections processed for POMC and $\mathrm{TH}$ were incubated in a cocktail containing rabbit anti-POMC (Phoenix Pharmaceuticals Inc., Belmont, CA, USA) at 1:5,000 and mouse anti-TH (Immunostar Inc., Hudson, WI, USA) at 1:1,000. Incubation time was 15$18 \mathrm{~h}$ in a rotary shaker at room temperature. The antiserum to POMC (27-52 amino acid sequence) was generated in rabbits against porcine POMC. The specificity of the mouse 
antiserum against TH was previously decribed (Van Bockstaele \& Pickel, 1993) and it specifically recognizes the catecholamine synthesizing enzyme.

Sections were then washed in 0.1 M TBS and incubated in a secondary antibody cocktail containing flourescein isothiocyanate (FITC) goat-anti-rabbit (1:100; Jackson ImmunoResearch Laboratories Inc., West Grove, PA, USA) and tetramethyl rhodamine isothiocyanate (TRITC) donkey anti-mouse (1:100; Jackson ImmunoResearch) prepared in $0.1 \%$ BSA and $0.25 \%$ Triton $\mathrm{X}-100$ in $0.1 \mathrm{M} \mathrm{TBS}$ for $2 \mathrm{~h}$ in the dark on a rotary shaker.

Sections processed for POMC and CRF were incubated in a cocktail containing rabbit anti-POMC at 1:5,000 and guinea pig anti-CRF (Peninsula Pharmaceuticals Inc., Belmont, CA, USA) at 1:1,000. Incubation time was $15-18 \mathrm{~h}$ in a rotary shaker at room temperature. The antiserum to CRF was raised in guinea pig and recognizes human and rat CRF. Sections were then washed in $0.1 \mathrm{M}$ TBS and incubated in a secondary antibody cocktail containing FITC goat-anti-rabbit (1:100; Jackson ImmunoResearch Laboratories Inc.) and TRITC donkey anti-guinea pig (1:100; Jackson ImmunoResearch Laboratories Inc.) prepared in $0.1 \% \mathrm{BSA}$ and $0.25 \%$ Triton X-100 in $0.1 \mathrm{M}$ TBS for $2 \mathrm{~h}$ in the dark on a rotary shaker.

Following incubation with the secondary antibodies, the tissues were washed thoroughly in 0.1 M TBS. Afterwards, the tissues were mounted on slides and allowed to dry in complete darkness. The slides were then dehydrated in a series of alcohols, soaked in xylene and coverslipped using DPX (Sigma-Aldrich Inc., St. Louis, MO, USA). A confocal microscope (Zeiss LSM 510 Meta, Carl Zeiss Inc., Thornwood, NY, USA) was 
used to visualize the immunofluorescence labeling and digital images were obtained and imported using the LSM 5 image browser (Carl Zeiss Inc.).

\section{Immunoelectron microscopy}

The rats were deeply anesthetized with sodium pentobarbital $(60 \mathrm{mg} / \mathrm{kg})$ and perfused transcardially through the ascending aorta with (1) $10 \mathrm{ml}$ heparinized saline, (2) $50 \mathrm{ml}$ of $3.75 \%$ acrolein (Electron Microscopy Sciences, Fort Washington, PA, USA), and $200 \mathrm{ml}$ of $2 \%$ formaldehyde in $0.1 \mathrm{M} \mathrm{PB}$, ph 7.4. Immediately after perfusion fixation, the brains were removed, sectioned into coronal slices and postfixed in the same fixative overnight at $4^{\circ} \mathrm{C}$.

Alternate $40-\mu \mathrm{m}$ thick sections through the rostrocaudal extent of the LC were processed for electron microscopic analysis of POMC and TH or POMC and CRF in the same section. Immunoperoxidase labeling was used to identify POMC immunoreactivity in sections processed for POMC and $\mathrm{TH}$ while immunoperoxidase labeling was used to identify CRF immunoreactivity for sections processed for POMC and CRF. Sections containing the LC were placed for $30 \mathrm{~min}$ in $1 \%$ sodium brohydride in $0.1 \mathrm{M}$ PB and collected into $0.1 \mathrm{M} \mathrm{PB}$ to remove reactive aldehydes. Then sections were rinsed extensively in $0.1 \mathrm{M} \mathrm{PB}$ and incubated in $0.5 \% \mathrm{BSA}$ in $0.1 \mathrm{M}$ TBS for $30 \mathrm{~min}$ followed by several rinses in $0.1 \mathrm{M}$ TBS. Tissue sections were incubated in primary antibody cocktail of rabbit anti-POMC (1:5000) and mouse anti-TH $(1: 1,000)$ for $15-18 \mathrm{~h}$ at room temperature. The following day, sections were rinsed three times in $0.1 \mathrm{M}$ TBS andincubated in biotinylated donkey anti-rabbit (1:400; Jackson ImmunoResearch Laboratories, Inc.) for $30 \mathrm{~min}$ followed by rinses in 0.1 M TBS. Subsequently, a 30minute incubation of avidin-biotin complex (Vector Laboratories, Burlingame, CA, USA) 
followed. For all incubations and washes, sections were continuously agitated with a rotary shaker. POMC was visualized by a 9-minute reaction in $22 \mathrm{mg}$ of 3,3'diaminobenzidine (Sigma-Aldrich Inc.) and $10 \mu 1$ of 30\% hydrogen peroxide in $100 \mathrm{ml}$ of 0.1 M TBS. Some sections were collected, dehydrated and coverslipped for light microscopic analysis of POMC immunoreactivity.

For gold-silver localization of TH (in sections processed for POMC and $\mathrm{TH}$ ) and POMC (in sections processed for POMC and CRF), sections were rinsed three times with 0.1 M TBS, followed by rinses with $0.1 \mathrm{M}$ PB and 0.01 phosphate buffered saline (PBS; $\mathrm{pH}$ 7.4). Sections were then incubated in a $0.2 \%$ gelatin-PBS and $0.8 \%$ BSA buffer for 10 min. This was followed by incubation in either goat anti-mouse IgG conjugate in $1 \mathrm{~nm}$ gold particles (Amersham Bioscience Corp., Piscataway, NJ, USA) for TH or goat antirabbit IgG conjugate in $1 \mathrm{~nm}$ gold particles (Amersham Bioscience Corp.) at room temperature for $2 \mathrm{~h}$. Sections were then rinsed in buffer containing the same concentration of gelatin and BSA as above and subsequently rinsed with 0.01 M PBS. Sections were then incubated in 2\% glutaraldehyde (Electron Microscopy Sciences) in $0.01 \mathrm{M}$ PBS for $10 \mathrm{~min}$ followed by washes in $0.01 \mathrm{M}$ PBS and $0.2 \mathrm{M}$ sodium citrate buffer (pH 7.4). A silver enhancement kit (Amersham Bioscience Corp.) was used for silver intensification of the gold particles. The optimal times for silver enhancement time were determined by empirical observation for each experiment and ranged 10-15 min. Following intensification, tissues were rinsed in $0.2 \mathrm{M}$ citrate buffer and $0.1 \mathrm{M} \mathrm{PB}$, and incubated in 2\% osmium tetroxide (Electron Microscopy Sciences) in $0.1 \mathrm{M} \mathrm{PB}$ for $1 \mathrm{~h}$, washed in $0.1 \mathrm{M} \mathrm{PB}$, dehydrated in an ascending series of ethanol followed by propylene oxide and flat embedded in Epon 812 (Electron Microscopy Sciences; Leranth and 
Pickel, 1989). Thin sections of approximately 50-100 nm in thickness were cut with a diamond knife (Diatome-US, Fort Washington, PA, USA) using a Leica Ultracut (Leica Microsystems, Wetzlar, Germany). Sections were collected on copper mesh grids, examined with an electron microscope (Morgagni, Fei Company, Hillsboro,OR, USA) and digital images were captured using the AMT advantage HR/HR-B CCD camera system (Advance Microscopy Techniques Corp., Danvers, MA, USA). Figures were assembled and adjusted for brightness and contrast in Adobe Photoshop.

\section{Control and data analysis}

Tissue sections for electron microscopy were taken from rats with the best immunocytochemical labeling and preservation of ultrastructural morphology. The quantitative approach used in the present study is well established and has been described previously (Van Bockstaele et al., 1996a; Van Bockstaele et al., 1996d; Van Bockstaele et al., 1998a). Control sections were run in parallel in which one of the primary antisera was omitted but the rest of the processing procedure was identical. Sections processed in the absence of primary antibody did not exhibit immunoreactivity. The region of the LC selected for electron microscopic analysis is shown in Figure 1A. For quantification of labeled profiles in $40 \mu \mathrm{m}$-thick sections immunolabeled before embedding for electron microscopy, we have observed that the collection of sections only from the surface of the section minimizes artifacts that may be associated with incomplete penetration of antisera. The analysis of tissue sections collected at the plastic-tissue interface ensured that both markers were detectable in all sections used for analysis (Chan et al., 1990). The cellular elements were identified based on the description of Peters and colleagues (Peters \& Palay, 1996; Peters et al., 1991). Somata contained a nucleus, Golgi apparatus 
and smooth endoplasmic reticulum. Proximal dendrites contained endoplasmic reticulum, were postsynaptic to axon terminals and were larger than $0.7 \mu \mathrm{m}$ in diameter. A terminal was considered to form a synapse if it showed a junctional complex, a restricted zone of parallel membranes with slight enlargement of the intercellular space, and/or associated with postsynaptic thickening. Asymmetric synapses were identified by thick postsynaptic densities (Gray's type I; (Gray et al., 1959), in contrast, symmetric synapses had thin densities (Gray's type II; (Gray et al., 1959) both pre- and postsynaptically. A nonsynaptic contact or apposition was defined as an axon terminal plasma membrane juxtaposed to that of a dendrite or soma devoid of recognizable membrane specializations and no intervening glial processes.

In sections dually labeled for POMC and $\mathrm{TH}$, the number of POMC axons and axon terminals was grouped from randomly selected sections from ultrathin sections taken from four nonadjacent sections from each animal $(n=5)$. At least four sections were examined per animal. From the surface of the individual epon block containing the tissue, at least four to eight ultrathin sections were collected. Fields of at least 11,000X magnification showing POMC-labeled axons and axon terminals, and TH-labeled profiles were captured and classified. This approach resulted in 405 POMC-labeled profiles. All potential neuronal targets of POMC-labeled axon terminals throughout the analysis were examined by defining their total associations with other profiles regardless of whether a membrane specialization was seen within the plane of section. These associations consisted of close appositions of neuronal plasma membranes not separated by glial processes. These profiles were considered since opioids as well as other peptides are released by exocytosis from nonsynaptic portions of plasmalemma (Thureson-Klein et 
al., 1986; Zhu et al., 1986; Karhunen et al., 2001). Postsynaptic targets considered included dendrites containing gold-silver labeling for TH, dendrites lacking gold-silver labeling for $\mathrm{TH}$, unlabeled terminals and glial processes. POMC-labeled profiles forming clear synaptic specializations were classified as symmetric (Gray’s Type II) or asymmetric (Gray's Type I). On the other hand, undefined contacts were characterized by a junctional complex that was not readily identifiable.

In sections dually labeled for POMC and CRF, POMC axons and axon terminals were studied from fields of at least 11,000X magnification found in at least four ultrathin sections taken from four sections from each animal $(n=5)$. Fields showing POMClabeled axons and axon terminals and CRF-labeled neuropil were captured and classified. This approach resulted in 657 POMC-labeled profiles. 


\section{Results}

By light microscopy, the LC was visualized using an antibody directed against POMC and appeared as dense immunoreactive processes distributed in the ventromedial aspect of the LC in the rostral pons (Fig. 1A). Fewer POMC-labeled fibers were found dorsolaterally. Immunofluorescence labeling for POMC and TH was visualized in coronal sections of the LC (Figs 1C-D). Immunocytochemical labeling for $\mathrm{TH}$ at rostral pontine levels showed considerable TH-immunoreactive dendrites extending from somata in the LC, medial and ventral to the fourth ventricle (Fig. 1B-D) consistent with previous studies (Van Bockstaele et al., 1995; Shipley et al., 1996). At caudal levels, THimmunoreactive dendrites of the peri-LC area, immediately medial to the core of LC neurons, was evidently less dense than that of the rostral levels (not shown). Conversely, the core of the LC exhibited a dense population of TH-immunoreactive somata (Fig. 1B and D). Immunocytochemical labeling for POMC revealed varicose processes within the peri-LC at rostral levels (Figs 1B-D). Numerous POMC-immunoreactive processes extended into the core of the LC where the somata of LC neurons are found (Figs 1B and D). POMC-immunoreactive fibers were morphologically heterogeneous. Some fibers were thin and beaded while others were thicker and lacked varicosities (Figs 1B-D).

\section{Ultrastructural analysis of POMC and TH}

At the electron microscopic level, immunoperoxidase labeling for POMC and immunogold-silver labeling for TH were localized within single sections of the LC. POMC immunoreactivity was identified primarily in unmyelinated axon terminals (Fig. 2). POMC-labeled dense core vesicles could be identified adjacent to the plasmalemma most commonly apposed to astrocytic process (Fig. 2A). Morever, POMC-labeled axon 
terminals contained abundant small clear spherical vesicles (Figs 2A-C). Often, peroxidase labeling for POMC rimmed the membranes of small clear spherical vesicles (Figs 2A-B). Large dense core vesicles were observed in POMC-labeled terminals (Figs $2 \&$ D) and contained abundant peroxidase labeling. TH-immunoreactivity was primarily localized to somatodendritic processes (Figs 2C-D), although occasionally axon terminals exhibited gold-silver labeling for $\mathrm{TH}$.

POMC-labeled axon terminals showed synaptic specializations with TH-labeled and -unlabeled dendrites (Figs 2B-C). Semiquantitative analysis revealed that POMClabeled axon terminals frequently contacted TH-labeled dendrites $(29 \% ; n=118)$. When synaptic specializations were identifiable, they were either of the symmetric, inhibitory type (Gray's type; Gray, 1959) or the asymmetric, excitatory type. Some of the POMClabeled axon terminals did not form clearly defined synaptic specializations with postsynaptic targets in the single planes of section analyzed (Fig. 2C). Of the 118 POMClabeled axon terminals that were in direct contact with TH-labeled dendrites, 39\% (46/118) were of the symmetric type while $18 \%$ (21/118) were asymmetric. The remainder did not form well defined synapses in the plane of sections analyzed. Approximately, $15 \%$ of the POMC-labeled axon terminals were occasionally apposed to other axon terminals. Frequently, appositions with other terminals lacked the specialized densities characteristic of axo-axonic synapses.

\section{Cellular interactions between POMC and CRF}

Immunofluorescence labeling for POMC and CRF was visualized in coronal sections in the rostral pontine tegmentum (Figs 3A-C). Immunocytochemical labeling for POMC and CRF exhibited a punctate pattern of staining and densely labeled fibers (Figs 
3A-C). POMC immunoreactivity was localized to CRF-labeled processes and this was more prominent in the peri-LC as compared to the core region (Fig. 3C).

\section{Ultrastructural analysis of POMC and CRF}

At the ultrastructural level, POMC immunolabeling showed a similar distribution as described above (Figs 4 and 5). CRF immunoreactivity was restricted to axons and axon terminals and was rarely seen in somata and dendrites consistent with previous findings (Van Bockstaele et al., 1996d; Van Bockstaele et al., 1998b). Of 657 POMClabeled axon terminals, where CRF immunoreactivity was present in the neuropil, 27\% (178/657) contained CRF immunoreactivity. Conversely, of 542 CRF-labeled terminals where POMC immunoreactivity was present in the neuropil, 33\% (178/542) were dually labeled. The dually-labeled terminals contained several recognizable small clear vesicles and one or more mitochondria (Figs 4A-D). Some of these also contained large dense core vesicles (Figs 4A-C). The dually-labeled axon terminals contacted primarily medium to small sized dendrites. Some of these terminals did not form recognizable synaptic specializations in the single planes of section analyzed. However, when synaptic specializations were recognizable, they were more frequently of the asymmetric type (Figs 4A, 4C and 5A-B). Of 178 POMC-labeled axon terminals that contained CRF immunoreactivity, $29 \%$ and $21 \%$ formed asymmetric and symmetric synapses (Figs 4D and $5 \mathrm{C}$ ), respectively. The remainder did not form identifiable synapses in sections examined. 


\section{Discussion}

The present findings demonstrate the first ultrastructural evidence that POMCimmunoreactive axon terminals form synaptic specializations with TH-containing dendrites in the LC. In addition, results show that POMC and CRF co-exist in single axon terminals in the LC. These data provide a neuroanatomical substrate whereby CRF afferents containing POMC derived peptides, such as $\beta$-endorphin, are positioned to impact the LC-NE system. This substrate could underlie activation of the brain NE system by stress and may serve to integrate autonomic components of the stress response associated with functions of LC neurons.

The present results provide the first ultrastructural description of POMC-labeled fibers in the rat LC. POMC fibers have been demonstrated in the LC in aquatic toad (Tuinhof et al., 1998). Our findings of the POMC distribution in the LC are consistent with that of $\beta$-endorphin, a peptide synthesized from POMC described in earlier studies, (Bloom et al., 1978a) where fibers course toward the middle third of the LC in the ventromedial aspect but are scant at caudal levels. By using dual immunoelectron microscopy, we provide the first ultrastructural evidence that POMC fibers form synaptic specializations with catecholamine-containing dendrites in the LC. In addition, we demonstrate that POMC-labeled fibers form primarily symmetric synapses that are correlated with inhibitory transmission, with TH-labeled dendrites in the LC (Peters \& Palay, 1996; Peters et al., 1991).

$\beta$-endorphin influences nociception (Foley et al., 1979; Yaksh et al., 1982; Bertolini et al., 1986; Baubet et al., 1994), cardiovascular (Laubie et al., 1977; Holaday, 1983), respiratory (Moss \& Friedman, 1978) and stress responses (Baubet et al., 1994). 
As such, intracoerulear injections of $\beta$-endorphin suppressed long lasting posture asymmetry and movement (Bertolini et al., 1986) and significantly elevated nociceptive threshold (Yaksh et al., 1982) which were reversed by naloxone, an opioid antagonist. In addition, $\beta$-endorphin administration via the cisterna magna caused a transient increase in blood pressure and heart rate followed by a delayed hypotension and bradycardia (Laubie et al., 1977). Loh and colleagues (Loh et al., 1976) demonstrated that $\beta$-endorphin inhibits striatal dopamine release in vitro. Furthermore, in situ hybridization study showed that acute stress increased POMC mRNA expression in the mediobasal hypothalamus (Baubet et al., 1994). Our present findings indicate that POMC modulates LC neurons directly in the dorsal pontine tegmentum. Hence, the central effects of $\beta$ endorphin described earlier may represent actions of this potent peptide on LC neurons as these neurons are engaged in similar activities.

Previous studies have shown that the arcuate nucleus (ARC) and NTS are enriched with POMC-immunoreactive perikarya (Schwartzberg \& Nakane, 1982; Gee et al., 1983). ARC and NTS are brain regions involved in a myriad of autonomic functions such as cardiovascular (Lu et al., 2002; Weston et al., 2003; Balan Junior et al., 2004; Guo \& Moazzami, 2004), nociception (Sun \& Yu, 2005; Tonosaki et al., 2005) and stress responses (Buller, 2003; Dayas et al., 2004; Helmreich et al., 2005; Kas et al., 2005; Sergeyev et al., 2005). Similarly, LC neurons have been implicated in autonomic functions including cardiovascular, respiratory and stress responses (Aston-Jones et al., 1991; Allen \& Cechetto, 1992; Cechetto \& Chen, 1992; Reis \& Golanov, 1997; Valentino et al., 1998; Machado, 2001). POMC fibers in the LC may be derived from the ARC and NTS since anatomical studies using retrograde tracing revealed that neurons 
from the ARC send projections to the LC (Luppi et al., 1995). In addition, we have previously demonstrated that efferent projections from the NTS monosynaptically innervate dendrites exhibiting TH-immunoreactivity in the rostral LC area where we found abundant POMC fibers (Van Bockstaele et al., 1999). The present study demonstrating dual-labeling for POMC-immunoreactive terminals and THimmunoreactive dendrites show that majority of the synapses identified were of symmetric type. These suggest that the ARC and NTS may be possible sources of POMC afferent fibers projecting to the LC that could regulate LC activity.

In the present study, immunofluorescence showed prominent co-localization of POMC and CRF terminals in the ventromedial aspect of the LC. However, there was little evidence of POMC and CRF co-localization in the dorsolateral aspect of the LC. The anatomical distribution of POMC and CRF co-localization is in contrast to the distribution of fibers dually labeled for enkephalin and CRF in the LC (Tjoumakaris et al., 2003) which was visualized more in the LC core and some observed dorsolaterally. This was confirmed at the ultrastructural level, where POMC and CRF dually labeled terminals were located primarily in the ventromedial aspect of the LC. With regard to the degree of co-localization with enkephalin ( $12 \%$ of enkephalin terminals; Tjoumakaris $e t$ al., 2003), the percentage of POMC-labeled terminals that exhibited CRF immunoreactivity in this study was greater. Therefore, although many POMC and CRF terminals were singly labeled, this study also shows a distinct population of terminals that co-localized both peptides.

The NTS is a potential source of POMC and CRF dually labeled terminals in the LC because it contains numerous CRF (Herbert \& Saper, 1990) and POMC 
(Schwartzberg \& Nakane, 1982) neurons. Taken with our previous demonstration that NTS efferents form synaptic specializations with catecholaminergic LC dendrites (Van Bockstaele et al., 1999), it is tempting to speculate that CRF neurons in the NTS that coexpress $\beta$-endorphin innervate LC neurons. Future studies would be useful to elucidate whether these terminals arise from the NTS.

Our findings also show that POMC/CRF afferents containing axon terminals form asymmetric (29\%) and symmetric (21\%) synapses with postsynaptic targets. Asymmetric synapses have been correlated with excitatory transmission whereas symmetric synapses have been correlated with inhibitory transmission (Gray 1959; Carlin et al., 1980; Carlin et al., 1981; Peters et al., 1991; Peters et al., 1996). These data suggest that POMC/CRF afferents may originate from different afferent nuclei (ARC vs NTS) based on their morphological heterogeneity. In addition, the heterogeneous morphological differentiation of the synapses may indicate co-existence with either excitatory or inhibitory amino acid transmitter such as glutamate or gamma-aminobutyric acid (GABA). We have shown that CRF forms primarily asymmetric synapses with LC dendrites and that some of these contain glutamate (30\%; Valentino et al., 2001). However, we also showed that some CRF terminals contain GABA (5\%) suggesting that, in the present study POMC/CRF terminals may co-express distinct amino acid transmitters, and by the virtue of this, exhibit distinct synaptic specializations. Future studies are required to determine whether POMC/CRF terminals co-express different amino acid transmitters.

In conclusion, our present results suggest that POMC is localized to efferents that target LC neurons, a circuit that may facilitate modulation of autonomic functions 
including nociceptive, cardiovascular and respiratory functions. In addition, afferents expressing both CRF and POMC as co-transmitters may be involved in regulation of stress responses known to be subserved by this region.

\author{
Abbreviations \\ $\mathrm{CRF}$, corticotropin-releasing factor; LC, locus coeruleus; POMC, proopiomelanocortin; \\ $\mathrm{TH}$, tyrosine hydroxylase;
}

\title{
Acknowledgements
}

This project was supported by the National Institutes of Health grants DA \#09082 and DA \#15395 to E.V.B. We thank Ms. Alicia Wilczynski for expert technical assistance. 


\section{References}

Allen, G.V. \& Cechetto, D.F. (1992) Functional and anatomical organization of cardiovascular pressor and depressor sites in the lateral hypothalamic area: I. Descending projections. J. Comp. Neurol., 315, 313-332.

Aston-Jones, G. \& Bloom, F.E. (1981a) Activity of norepinephrine-containing locus coeruleus neurons in behaving rats anticipates fluctuations in the sleep-waking cycle. J. Neurosci., 1, 876-886.

Aston-Jones, G. \& Bloom, F.E. (1981b) Nonrepinephrine-containing locus coeruleus neurons in behaving rats exhibit pronounced responses to non-noxious environmental stimuli. J. Neurosci., 1, 887-900.

Aston-Jones, G., Foote, S.L. \& Bloom, F.E. (1984) Anatomy and physiology of locus coeruleus neurons: functional implications. In Ziegler, M., Lake, C.R. (eds.) Norepinephrine (Frontiers of Clinical Neuroscience). Williams and Wilkins, Baltimore, pp. 92-116.

Aston-Jones, G., Foote, S.L. \& Segal, M. (1985) Impulse conduction properties of noradrenergic locus coeruleus axons projecting to monkey cerebrocortex. Neuroscience, 15, 765-777.

Aston-Jones, G., Rajkowski, J., Kubiak, P. \& Alexinsky, T. (1994) Locus coeruleus neurons in monkeys are selectively activated by attended cues in a vigilance task. J. Neurosci., 14, 4467-4480.

Aston-Jones, G., Shipley, M.T., Chouvet, G., Ennis, M., Van Bockstaele, E., Pieribone, V., Shiekhattar, R., Akaoka, H., Drolet, G. \& Astier, B. (1991) Afferent regulation of locus coeruleus neurons: anatomy, physiology and pharmacology. Prog. Brain Res., 88, 47-75.

Balan Junior, A., Caous, C.A., Yu, Y.G. \& Lindsey, C.J. (2004) Barosensitive neurons in the rat tractus solitarius and paratrigeminal nucleus: a new model for medullary, cardiovascular reflex regulation. Can. J. Physiol. Pharmacol., 82, 474-484.

Baubet, V., Fevre-Montange, M., Gay, N., Debilly, G., Bobillier, P. \& Cespuglio, R. (1994) Effects of an acute immobilization stress upon proopiomelanocortin (POMC) mRNA levels in the mediobasal hypothalamus: a quantitative in situ hybridization study. Brain Res. Mol. Brain Res., 26, 163-168.

Bertolini, A., Vergoni, A.V., Poggioli, R. \& Gessa, G.L. (1986) Morphine and betaendorphin antagonize posture and locomotor disorders induced by the injection of ACTH 1-24 in the rat locus coeruleus. Life Sci., 38, 373-377.

Bloom, F., Battenberg, E., Rossier, J., Ling, N. \& Guillemin, R. (1978a) Neurons containing beta-endorphin in rat brain exist separately from those containing enkephalin: immunocytochemical studies. Proc. Natl. Acad. Sci. USA, 75, 15911595.

Bloom, F.E., Rossier, J., Battenberg, E.L., Bayon, A., French, E., Henriksen, S.J., Siggins, G.R., Segal, D., Browne, R., Ling, N. \& Guillemin, R. (1978b) betaendorphin: cellular localization, electrophysiological and behavioral effects. $A d v$. Biochem. Psychopharmacol., 18, 89-109.

Buller, K.M. (2003) Neuroimmune stress responses: reciprocal connections between the hypothalamus and the brainstem. Stress, 6, 11-17. 
Carlin, R.K., Grab, D.J., Cohen, R.S. \& Siekevitz, P. (1980) Isolation and characterization of postsynaptic densities from various brain regions: enrichment of different types of postsynaptic densities. J. Cell Biol., 86, 831-845.

Carlin, R.K., Grab, D.J. \& Siekevitz, P. (1981) Function of a calmodulin in postsynaptic densities. III. Calmodulin-binding proteins of the postsynaptic density. J. Cell Biol., 89, 449-455.

Cechetto, D.F. \& Chen, S.J. (1992) Hypothalamic and cortical sympathetic responses relay in the medulla of the rat. Am. J. Physiol., 263, R544-552.

Chan, J., Aoki, C. \& Pickel, V.M. (1990) Optimization of differential immunogold-silver and peroxidase labeling with maintenance of ultrastructure in brain sections before plastic embedding. J. Neurosci. Methods, 33, 113-127.

Cummings, S., Elde, R., Ells, J. \& Lindall, A. (1983) Corticotropin-releasing factor immunoreactivity is widely distributed within the central nervous system of the rat: an immunohistochemical study. J. Neurosci., 3, 1355-1368.

Curtis, A.L., Lechner, S.M., Pavcovich, L.A. \& Valentino, R.J. (1997) Activation of the locus coeruleus noradrenergic system by intracoerulear microinfusion of corticotropin-releasing factor: effects on discharge rate, cortical norepinephrine levels and cortical electroencephalographic activity. J. Pharmacol. Exp. Ther., 281, 163-172.

Dayas, C.V., Buller, K.M. \& Day, T.A. (2004) Hypothalamic paraventricular nucleus neurons regulate medullary catecholamine cell responses to restraint stress. $J$. Comp. Neurol., 478, 22-34.

Drolet, G., Van Bockstaele, E.J. \& Aston-Jones, G. (1992) Robust enkephalin innervation of the locus coeruleus from the rostral medulla. J. Neurosci., 12, 3162-3174.

Fallon, J.H. \& Leslie, F.M. (1986) Distribution of dynorphin and enkephalin peptides in the rat brain. J. Comp. Neurol., 249, 293-336.

Foley, K.M., Kourides, I.A., Inturrisi, C.E., Kaiko, R.F., Zaroulis, C.G., Posner, J.B., Houde, R.W. \& Li, C.H. (1979) beta-Endorphin: analgesic and hormonal effects in humans. Proc. Natl. Acad. Sci. USA, 76, 5377-5381.

Foote, S.L., Bloom, F.E. \& Aston-Jones, G. (1983) Nucleus locus ceruleus: new evidence of anatomical and physiological specificity. Physiol. Rev., 63, 844-914.

Gee, C.E., Chen, C.L., Roberts, J.L., Thompson, R. \& Watson, S.J. (1983) Identification of proopiomelanocortin neurones in rat hypothalamus by in situ cDNA-mRNA hybridization. Nature, 306, 374-376.

Gray, E.G. (1959) Axosomatic and axo-dendritic synapses of the cerebral cortex: an electron microscopic study. J. Anat., 93, 420-433.

Guo, Z.L. \& Moazzami, A.R. (2004) Involvement of nuclei in the hypothalamus in cardiac sympathoexcitatory reflexes in cats. Brain Res., 1006, 36-48.

Helmreich, D.L., Parfitt, D.B., Lu, X.Y., Akil, H. \& Watson, S.J. (2005) Relation between the hypothalamic-pituitary-thyroid (HPT) axis and the hypothalamicpituitary-adrenal (HPA) axis during repeated stress. Neuroendocrinology, 81, 183-192.

Herbert, H. \& Saper, C.B. (1990) Cholecystokinin-, galanin-, and corticotropin-releasing factor-like immunoreactive projections from the nucleus of the solitary tract to the parabrachial nucleus in the rat. J. Comp. Neurol., 293, 581-598. 
Holaday, J.W. (1983) Cardiovascular effects of endogenous opiate systems. Annu. Rev. Pharmacol. Toxicol., 23, 541-594.

Karhunen, T., Vilim, F.S., Alexeeva, V., Weiss, K.R. \& Church, P.J. (2001) Targeting of peptidergic vesicles in cotransmitting terminals. J. Neurosci., 21, RC127.

Kas, M.J., Bruijnzeel, A.W., Haanstra, J.R., Wiegant, V.M. \& Adan, R.A. (2005) Differential regulation of agouti-related protein and neuropeptide $\mathrm{Y}$ in hypothalamic neurons following a stressful event. J. Mol. Endocrinol., 35, 159164.

Laubie, M., Schmitt, H., Vincent, M. \& Remond, G. (1977) Central cardiovascular effects of morphinomimetic peptides in dogs. Eur. J. Pharmacol., 46, 67-71.

Lavicky, J. \& Dunn, A.J. (1993) Corticotropin-releasing factor stimulates catecholamine release in hypothalamus and prefrontal cortex in freely moving rats as assessed by microdialysis. J. Neurochem., 60, 602-612.

Loh, H.H., Brase, D.A., Sampath-Khanna, S., Mar, J.B., Way, E.L. \& Li, C.H. (1976) beta-Endorphin in vitro inhibition of striatal dopamine release. Nature, 264, 567568.

Lu, Y., Zou, C.J., Huang, D.W. \& Tang, C.S. (2002) Cardiovascular effects of urotensin II in different brain areas. Peptides, 23, 1631-1635.

Luppi, P.H., Aston-Jones, G., Akaoka, H., Chouvet, G. \& Jouvet, M. (1995) Afferent projections to the rat locus coeruleus demonstrated by retrograde and anterograde tracing with cholera-toxin b subunit and Phaseolus vulgaris leucoagglutinin. Neuroscience, 65, 119-160.

Machado, B.H. (2001) Neurotransmission of the Cardiovascular Reflexes in the Nucleus Tractus Solitarii of Awake Rats. Ann. NY Acad. Sci., 940, 179-196.

Mansour, A., Fox, C.A., Akil, H. \& Watson, S.J. (1995) Opioid-receptor mRNA expression in the rat CNS: anatomical and functional implications. Trends Neurosci., 18, 22-29.

Mansour, A., Fox, C.A., Burke, S., Meng, F., Thompson, R.C., Akil, H. \& Watson, S.J. (1994) $\mathrm{Mu}$, delta, and kappa opioid receptor mRNA expression in the rat CNS: an in situ hybridization study. J. Comp. Neurol., 350, 412-438.

McCormick, D.A., Pape, H.C. \& Williamson, A. (1991) Actions of norepinephrine in the cerebral cortex and thalamus: implications for function of the central noradrenergic system. Prog. Brain Res., 88, 293-305.

Miyawaki, T., Kawamura, H., Komatsu, K. \& Yasugi, T. (1991) Chemical stimulation of the locus coeruleus: inhibitory effects on hemodynamics and renal sympathetic nerve activity. Brain Res., 568, 101-108.

Morilak, D.A., Fornal, C.A. \& Jacobs, B.L. (1987a) Effects of physiological manipulations on locus coeruleus neuronal activity in freely moving cats. II. Cardiovascular challenge. Brain Res., 422, 24-31.

Morilak, D.A., Fornal, C.A. \& Jacobs, B.L. (1987b) Effects of physiological manipulations on locus coeruleus neuronal activity in freely moving cats. III. Glucoregulatory challenge. Brain Res., 422, 32-39.

Moss, I.R. \& Friedman, E. (1978) beta-Endorphin: effects on respiratory regulation. Life Sci., 23, 1271-1276.

Peters, A., Palay, S.L. \& Webster, H.d. (1991) The Fine Structure of the Nervous System. Oxford University Press, New York. 
Peters, A. \& Palay, S.L. (1996) The morphology of synapses. J. Neurocytol., 25, 687700.

Reis, D.J. \& Golanov, E.V. (1997) Autonomic and vasomotor regulation. Int. Rev. Neurobiol., 41, 121-149.

Rubinstein, M., Mogil, J.S., Japon, M., Chan, E.C., Allen, R.G. \& Low, M.J. (1996) Absence of opioid stress-induced analgesia in mice lacking beta-endorphin by site-directed mutagenesis. Proc. Natl. Acad. Sci. USA, 93, 3995-4000.

Schwartzberg, D.G. \& Nakane, P.K. (1982) Ontogenesis of adrenocorticotropin-related peptide determinants in the hypothalamus and pituitary gland of the rat. Endocrinology, 110, 855-864.

Sergeyev, V., Fetissov, S., Mathe, A.A., Jimenez, P.A., Bartfai, T., Mortas, P., Gaudet, L., Moreau, J.L. \& Hokfelt, T. (2005) Neuropeptide expression in rats exposed to chronic mild stresses. Psychopharmacology (Berl), 178, 115-124.

Shipley, M.T., Fu, L., Ennis, M., Liu, W.L. \& Aston-Jones, G. (1996) Dendrites of locus coeruleus neurons extend preferentially into two pericoerulear zones. J. Comp. Neurol., 365, 56-68.

Smagin, G.N., Swiergiel, A.H. \& Dunn, A.J. (1995) Corticotropin-releasing factor administered into the locus coeruleus, but not the parabrachial nucleus, stimulates norepinephrine release in the prefrontal cortex. Brain Res. Bull., 36, 71-76.

Sun, Y.G. \& Yu, L.C. (2005) Interactions of galanin and opioids in nociceptive modulation in the arcuate nucleus of hypothalamus in rats. Regul. Peptides, 124, $37-43$.

Svensson, T.H. (1987) Peripheral, autonomic regulation of locus coeruleus noradrenergic neurons in brain: putative implications for psychiatry and psychopharmacology. Psychopharmacology (Berl), 92, 1-7.

Swanson, L.W., Sawchenko, P.E., Rivier, J. \& Vale, W.W. (1983) Organization of ovine corticotropin-releasing factor immunoreactive cells and fibers in the rat brain: an immunohistochemical study. Neuroendocrinology, 36, 165-186.

Tempel, A. \& Zukin, R.S. (1987) Neuroanatomical patterns of the mu, delta and kappa opioid receptors of rat brain as determined by quantitative in vitro autoradiography. Proc. Natl. Acad. Sci. USA, 84, 4308-4312.

Thureson-Klein, A., Klein, R.L. \& Zhu, P.C. (1986) Exocytosis from large dense cored vesicles as a mechanism for neuropeptide release in the peripheral and central nervous system. Scan. Electron Microsc., 179-187.

Tjoumakaris, S.I., Rudoy, C., Peoples, J., Valentino, R.J. \& Van Bockstaele, E. (2003) Cellular interactions between axon terminals containing endogenous opioid peptides or corticotropin-releasing factor in the rat locus coeruleus and surrounding dorsal pontine tegmentum. J. Comp. Neurol., 466, 445-456.

Tonosaki, Y., Nishiyama, K., Roubos, E.W. \& Sugiura, Y. (2005) alpha-Melanophorestimulating hormone (alpha-MSH) antagonizes interleukin-1beta-induced hyperalgesia and Fos expression in the paraventricular and arcuate nucleus of the rat. Neuroendocrinology, 81, 167-173.

Tuinhof, R., Ubink, R., Tanaka, S., Atzori, C., van Strien, F.J. \& Roubos, E.W. (1998) Distribution of pro-opiomelanocortin and its peptide end products in the brain and hypophysis of the aquatic toad, Xenopus laevis. Cell Tissue Res., 292, 251-265. 
Vale, W., Spiess, J., Rivier, C. \& Rivier, J. (1981) Characterization of a 41-residue ovine hypothalamic peptide that stimulates secretion of corticotropin and betaendorphin. Science, 213, 1394-1397.

Valentino, R.J., Curtis, A.L., Page, M.E., Pavcovich, L.A., Lechner, S.M. \& Van Bockstaele, E.J. (1998) The locus coeruleus-noradrenergic system as an integrator of stress responses. In Morrison, A.R., Fluharty, S.J. (eds.) Progress in Psychobiology and Physiological Psychology. Academic Press, San Diego, CA, pp. 91-126.

Valentino, R.J., Foote, S.L. \& Aston-Jones, G. (1983) Corticotropin-releasing factor activates noradrenergic neurons of the locus coeruleus. Brain Res., 270, 636-367.

Valentino, R.J., Page, M.E., Van Bockstaele, E.J. \& Aston-Jones, G. (1992) Corticotropin-releasing factor innervation of the locus coeruleus region: distribution of fibers and sources of input. Neuroscience, 48, 689-705.

Valentino, R.J., Rudoy, C., Saunders, A., Liu, X.-B. \& Van Bockstaele, E.J. (2001) Corticotropin-releasing factor is preferentially colocalized with excitatory rather than inhibitory amino acids in axon terminals in the peri-locus coeruleus region. Neuroscience, 106, 375-384.

Van Bockstaele, E.J., Branchereau, P. \& Pickel, V.M. (1995) Morphologically heterogeneous met-enkephalin terminals form synapses with tyrosine hydroxylase-containing dendrites in the rat nucleus locus coeruleus. J. Comp. Neurol., 363, 423-438.

Van Bockstaele, E.J. \& Chan, J. (1997) Electron microscopic evidence for coexistence of leucine5-enkephalin and gamma-aminobutyric acid in a subpopulation of axon terminals in the rat locus coeruleus region. Brain Res., 746, 171-182.

Van Bockstaele, E.J., Colago, E.E.O. \& Aicher, S. (1998a) Light and electron microscopic evidence for topographic and monosynaptic projections from neurons in the ventral medulla to noradrenergic dendrites in the rat locus coeruleus. Brain Res., 784, 123-138.

Van Bockstaele, E.J., Colago, E.E.O., Cheng, P., Moriwaki, A., Uhl, G.R. \& Pickel, V.M. (1996a) Ultrastructural evidence for prominent distribution of the mu-opioid receptor at extrasynaptic sites on noradrenergic dendrites in the rat nucleus locus coeruleus. J. Neurosci., 16, 5037-5048.

Van Bockstaele, E.J., Colago, E.E.O., Moriwaki, A. \& Uhl, G.R. (1996b) Mu-opioid receptor is located on the plasma membrane of dendrites that receive asymmetric synapses from axon terminals containing leucine-enkephalin in the rat nucleus locus coeruleus. J. Comp. Neurol., 376, 65-74.

Van Bockstaele, E.J., Colago, E.E.O. \& Pickel, V.M. (1996c) Enkephalin terminals form inhibitory-type synapses on neurons in the rat nucleus locus coeruleus that project to the medial prefrontal cortex. Neuroscience, 71, 429-442.

Van Bockstaele, E.J., Colago, E.E.O. \& Valentino, R.J. (1996d) Corticotropin-releasing factor-containing axon terminals synapse onto catecholamine dendrites and may presynaptically modulate other afferents int he rostral pole of the nucleus locus coeruleus in the rat brain. J. Comp. Neurol., 364, 523-534.

Van Bockstaele, E.J., Colago, E.E.O. \& Valentino, R.J. (1998b) Amygdaloid corticotropin-releasing factor targets locus coeruleus dendrites: substrate for the co-ordination of emotional and cognitive limbs of the stress response. $J$. Neuroendocrin., 10, 743-757. 
Van Bockstaele, E.J., Peoples, J. \& Telegan, P. (1999) Efferent projections of the nucleus of the solitary tract to peri-locus coeruleus dendrites in rat brain: evidence for a monosynaptic pathway. J. Comp. Neurol., 412, 410-428.

Van Bockstaele, E.J. \& Pickel, V.M. (1993) Ultrastructure of serotonin-immunoreactive terminals in the core and shell of the rat nucleus accumbens: cellular substrates for interactions with catecholamine afferents. J. Comp. Neurol., 334, 603-617.

Van Bockstaele, E.J., Saunders, A., Commons, K., Liu, X.-B. \& Peoples, J. (2000) Evidence for co-existence of enkephalin and glutamate in axon terminals and cellular sites for functional interactions of their receptors in the rat locus coeruleus. J. Comp. Neurol., 417, 103-114.

Weston, M., Wang, H., Stornetta, R.L., Sevigny, C.P. \& Guyenet, P.G. (2003) Fos expression by glutamatergic neurons of the solitary tract nucleus after phenylephrine-induced hypertension in rats. J. Comp. Neurol., 460, 525-541.

Xu, G.-P., Van Bockstaele, E.J., Reyes, B.A., Bethea, T. \& Valentino, R.J. (2004) Chronic morphine sensitizes the brain norepinephrine system to corticotropinreleasing factor and stress. J. Neuroscience, 24, 8193-8197.

Yaksh, T.L., Gross, K.E. \& Li, C.H. (1982) Studies on the intrathecal effect of betaendorphin in primate. Brain Res., 241, 261-269.

Zhu, P.C., Thureson-Klein, A. \& Klein, R.L. (1986) Exocytosis from large dense cored vesicles outside the active synaptic zones of terminals within the trigeminal subnucleus caudalis: a possible mechanism for neuropeptide release.

Neuroscience, 19, 43-54. 


\section{Figure Legends}

Figure 1. A. Brightfield photomicrographs of proopiomelanocortin (POMC) in the locus coeruleus (LC). Arrows indicate individual POMC-labeled processes. Note that many are highly beaded and thin. Inset in panel A shows a schematic diagram adapted from the rat brain atlas of Swanson (1992) depicting the region sampled. In the inset, arrows indicate dorsal (D) and medial (M) orientation of the sections illustrated. B-D. Confocal fluorescence photomicrographs of POMC (arrowheads) labeled with fluorescein isothiocyanate (green) and tyrosine hydroxylase (TH; arrows) labeled with rhodamine isothiocyanate (red) in the LC. Abundant POMC-labeled processes are associated with TH-labeled dendrites (C). This association extends into the LC somatic region (B and D). Scale bars, $100 \mu \mathrm{m}$. Abbreviations: scp, superior cerebellar peduncle; D, dorsal; IV, fourth ventricle; M, medial; mlf, medial longitudinal fasciculus; moV, motor root of the trigeminal nucleus; $\mathrm{V}$, motor nucleus of the trigeminal nucleus.

Figure 2. Electron photomicrographs showing peroxidase labeling for proopiomelanocortin (POMC) and gold-silver labeling for tyrosine hydroxylase (TH) in the locus coeruleus (LC). A. Peroxidase labeling can be seen in a POMC-labeled terminal (POMC-t) that contains dense core vesicles (dcv). Several unlabeled terminals (ut) that contain unlabeled dense core vesicles (udcv) can be seen in the neuropil. B. A peroxidase-labeled POMC-t forms a symmetric synapse (arrow) with an unlabeled dendrite (ud). C. A peroxidase-labeled POMC-t that contains dev is directly contacted (double arrow) with a TH-labeled dendrite (TH). Arrowheads indicate gold-silver labeling for TH. Arrows point to symmetric synapses formed by unlabeled terminals (ut). 
D. Another peroxidase-labeled POMC-t forms a symmetric synapse (arrow) with a TH-d. Scale bars, $0.50 \mu \mathrm{m}$. ma, myelinated axon.

Figure 3. Confocal fluorescence photomicrographs showing co-localization of proopiomelanocortin (POMC) and corticotropin-releasing factor (CRF) in the locus coeruleus (LC). A and A1. CRF-labeling was detected by rhodamine isothiocyanate (red). Arrows point to individual CRF-labeled varicose processes that contain POMC. Arrowheads point to varicose processes that contain CRF. B and B1. POMC-labeling was detected by fluorescein isothiocyanate (green). Arrows point to individual POMClabeled varicose processes that contain CRF. Arrowheads point to varicose processes that contain POMC. C and C1. Merged image. Arrows point to POMC- and CRF-dual labeled varicose processes. Arrowheads point to either POMC or CRF varicose processes. Scale bars, $100 \mu \mathrm{m}$.

Figure 4. Electron photomicrographs showing convergence and co-existence of proopiomelanocortin (POMC) and corticotropin-releasing factor (CRF) in the locus coeruleus (LC). A. A gold-silver labeled (arrowheads) POMC terminal (POMC-t) and peroxidase-labeled CRF axon terminal (CRF-t) synapse (curved arrows) with a common dendrite (d). Another peroxidase-labeled CRF-t can also be identified in the neuropil. B. Two axon terminals containing both peroxidase labeling for CRF and gold-silver labeling (arrowheads) for POMC contact (arrow) a dendrite (d). C-D. Axon terminals containing both peroxidase labeling for CRF and gold-silver labeling (arrowheads) for POMC $($ POMC + CRF-t) contact dendrites (d) in the LC. Scale bars, $0.5 \mu \mathrm{m}$.

Figure 5. Electron photomicrographs showing synaptic specializations formed by proopiomelanocortin (POMC) and corticotropin-releasing factor (CRF) axon terminals in 
the locus coeruleus (LC). A-B. Gold-silver labeling for POMC (arrowheads) and peroxidase-labeling for $\mathrm{CRF}(\mathrm{POMC}+\mathrm{CRF}-\mathrm{t})$ can be found in axon terminal forming asymmetric synapses (arrows) with dendrites (d). C. A POMC+ CRF-t forms a symmetric synapse (curved arrow) with a dendrite (d). Scale bars, $0.5 \mu \mathrm{m}$. 